\title{
Erratum to: Deletion of glucose-inhibited division (gidA) gene alters the morphological and replication characteristics of Salmonella enterica Serovar typhimurium
}

\author{
Daniel C. Shippy $\cdot$ Joseph A. Heintz • \\ Ralph M. Albrecht • Nicholas M. Eakley • \\ Ashok K. Chopra $\cdot$ Amin A. Fadl
}

Published online: 11 January 2012

(C) Springer-Verlag 2012

\section{Erratum to: Arch Microbiol}

DOI 10.1007/s00203-011-0769-7

In the original version, co-author Ashok K. Chopra was inadvertently not listed in the author group. The correct order of authors is given below:

Daniel C. Shippy, Joseph A. Heintz, Ralph M. Albrecht, Nicholas M. Eakley, Ashok K. Chopra, Amin A. Fadl

In addition, the below information was missed in “Acknowledgments" section:

Acknowledgments We thank Dr. Ashok Chopra's research group, University of Texas Medical Branch, Galveston, Texas, USA, for their helpful discussion. The NIH/NIAID grant AI064389 (AKC) is fully acknowledged, which supported in part these studies.

The online version of the original article can be found under doi:10.1007/s00203-011-0769-7.

D. C. Shippy · J. A. Heintz - R. M. Albrecht .

N. M. Eakley · A. A. Fadl (ه)

Department of Animal Sciences,

University of Wisconsin-Madison, 1675 Observatory Drive,

Madison, WI 53706, USA

e-mail: fadl@wisc.edu

\section{A. K. Chopra}

Department of Microbiology and Immunology,

University of Texas, Medical Branch, 301 University Blvd,

Galveston, TX 77555, USA 